\title{
Retraction Note: Assessing the influence of highway and high-speed railway construction on local climate using Landsat images in karst areas
}

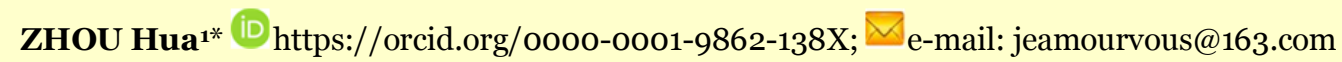

LUO Yang 1 iD https://orcid.org/oooo-0003-2327-4306 e-mail: luoyang0317@tom.com

DING Fang-jun1 iD https://orcid.org/oooo-0oo2-4181-6896 e-mail: ding3920034@163.com

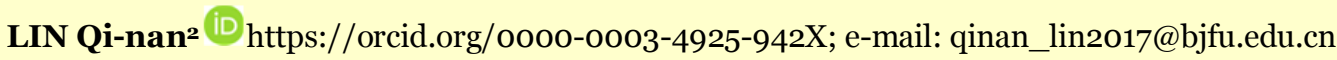

* Corresponding author

1 Guizhou Academy of Forestry, No. 382 Fuyuan South Road Nanming District, Guiyang 550ooo, China

2 Beijing Forestry University, Forestry College, No.35 Tsinghua East Road, Haidian District, Beïing 10oo83, China

Citation: Zhou H, Luo Y, Ding FJ, Lin QA (2019) Retraction to: Assessing the influence of highway and high-speed railway construction on local climate using Landsat images in karst areas 17(9). https://doi.org/10.1007/s11629-019-5847-3

(C) Science Press, Institute of Mountain Hazards and Environment, CAS and Springer-Verlag GmbH Germany, part of Springer Nature 2020

\section{Retraction to: J. Mt. Sci. (2019) 16(7): 1584-1597. https://doi.org/10.1007/s11629-018-5220-y}

The Editor-in-Chief has retracted this article [1] because it significantly overlaps with a previously published article by Nedbal and Brom [2]. All authors agree to this retraction.

[1] Zhou H, Luo Y, Ding F, et al. (2019) Assessing the influence of highway and high-speed railway construction on local climate using Landsat images in karst areas. Journal of Mountain Science 16(7): 15841597. https://doi.org/10.1007/s11629-018-5220-y

[2] Nedbal V, Brom J (2018) Impact of highway construction on land surface energy balance and local climate derived from LANDSAT satellite data. Science of the Total Environment 633: 658-667. https://doi.org/10.1016/j.scitotenv.2018.03.220 